\title{
MEDIASTINAL HISTOPLASMOSIS: REPORT OF THE FIRST TWO BRAZILIAN CASES OF MEDIASTINAL GRANULOMA
}

\begin{abstract}
SUMMARY
This report documents the first two Brazilian cases of mediastinal granuloma due to histoplasmosis, presenting selected aspects on the diagnosis. Tissue samples revealing histoplasmosis were obtained from each of the patients by mediastinoscopy and thoracotomy. In the second patient, a subcarinal calcified mass eroded into the bronchial tree, leading to secondary bilateral aspiration pneumonitis one week after thoracotomy.

Although rare, histoplasmosis should be included in the differential diagnosis of mediastinal granuloma, specially if there are calcifications greater than $10 \mathrm{~mm}$ in dimension.
\end{abstract}

KEYWORDS: Histoplasmosis; Histoplasma capsulatum var. capsulatum; Mediastinal histoplasmosis; Mediastinal granuloma.

\section{INTRODUCTION}

Classic histoplasmosis is caused by the thermal dimorphic fungus Histoplasma capsulatum var. capsulatum (H. capsulatum). The usual manifestation is an acute, self-limited, flu-like respiratory illness, however, depending on the host's defenses and extent of inoculation, a variety of clinical manifestations may result ${ }^{5}$.

The resolution process of granulomatous lymphadenitis due to $H$. capsulatum may cause mediastinal disease. Mediastinal granuloma and fibrosing mediastinitis are both well-documented, though uncommon, mediastinal sequela of infection. Their formation depends on the lymph node caseation and the degree of fibrotic response incited to the organism? .

There are three clinical syndromes associated with mediastinal histoplasmosis: mediastinal adenitis, mediastinal granuloma and fibrosing mediastinitis ${ }^{14}$. In Brazil, only the latter has been previously documented $^{8}$. To present the first two cases of mediastinal granuloma warrant this report. A brief review of the pertinent literature is presented.

\section{CASE REPORTS}

CASE 1: A 62-year-old man, was seen in May, 2002 in Salvador (BA) complaining of nonproductive cough during the previous two months. He had smoked two packs of cigarettes for many years. Physical examination was entirely normal. A computed tomographic (CT) scan of the thorax (Fig. 1) showed a pretracheal mass of $1.7 \mathrm{~cm}$ and increased mediastinal lymphadenopathy in the right paratracheal region. Mediastinoscopic examination showed a pretracheal mass with no fibrosis or apparent damage to the adjacent structures. Samples of the right paratracheal lymph nodes and the mass were taken for histopathological examination, which showed large foci of caseous

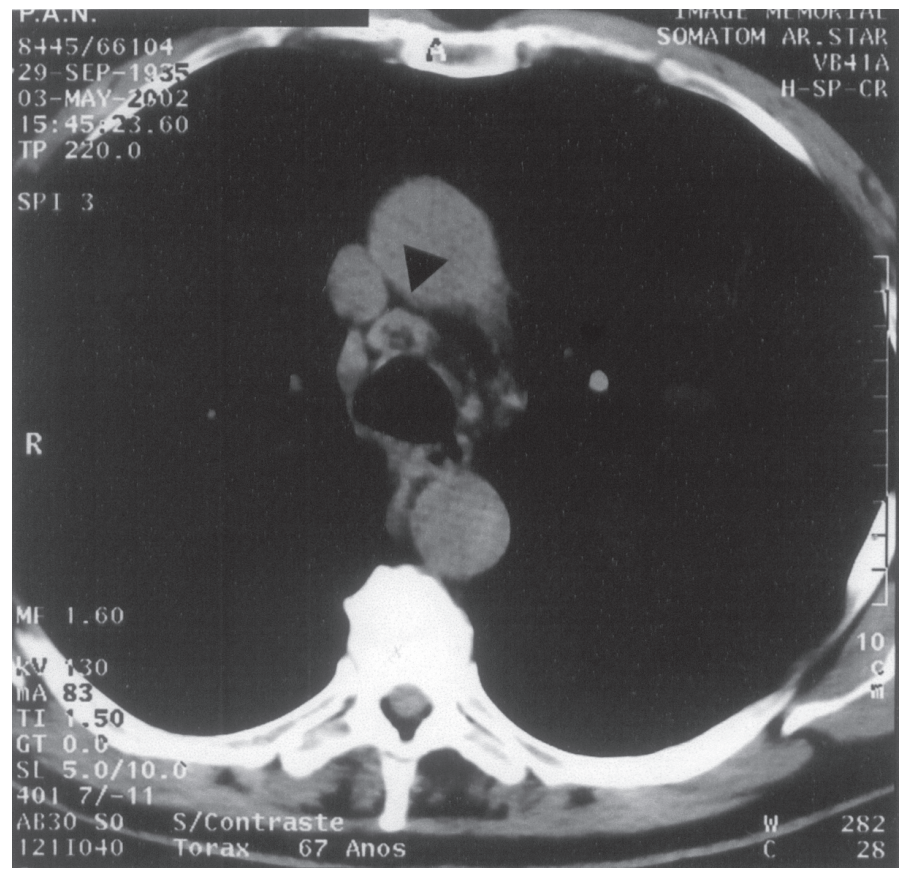

Fig. 1 - CASE 1: Computed tomographic scan of the chest showing a $1.7 \mathrm{~cm}$ noncalcified, necrotic pretracheal mass (arrow). 
necrosis and fibrosis. A Mantoux skin test was applied, developing 13 $\mathrm{mm}$ induration. The patient was referred for treatment of a presumed tuberculosis. However, microscopic examination of specially stained specimens was performed. The test for acid-fast organisms was negative. On Gomori-Grocott methenamine silver stain (GMS) organisms similar to $H$. capsulatum were present within caseous areas. Treatment with itraconazole, $100 \mathrm{mg}$ BID was initiated; after six months the patient was asymptomatic.

CASE 2: A 23-year-old man was seen on September 23, 2002 in Recife (PE) complaining of fever, substernal chest pain, and cough lasting one month. During the period of clinical investigation the patient had an episode of foul sputum productive cough. Chest CT demonstrated a $4.5 \mathrm{~cm}$ subcarinal mass with scattered calcifications (Fig. 2). On October 6, an exploratory thoracotomy was performed. Microscopic examination of the biopsy specimen disclosed calcified necrotic debris and chronic inflammation with a border of palisading histiocytes and Langhans' giant cells. Slides stained with GMS showed many yeast cells resembling $H$. capsulatum within the areas of caseous necrosis. Ziehl-Neelsen stain for acid-fast bacilli was negative. Serologic test to histoplasmosis (immunodiffusion) was positive.

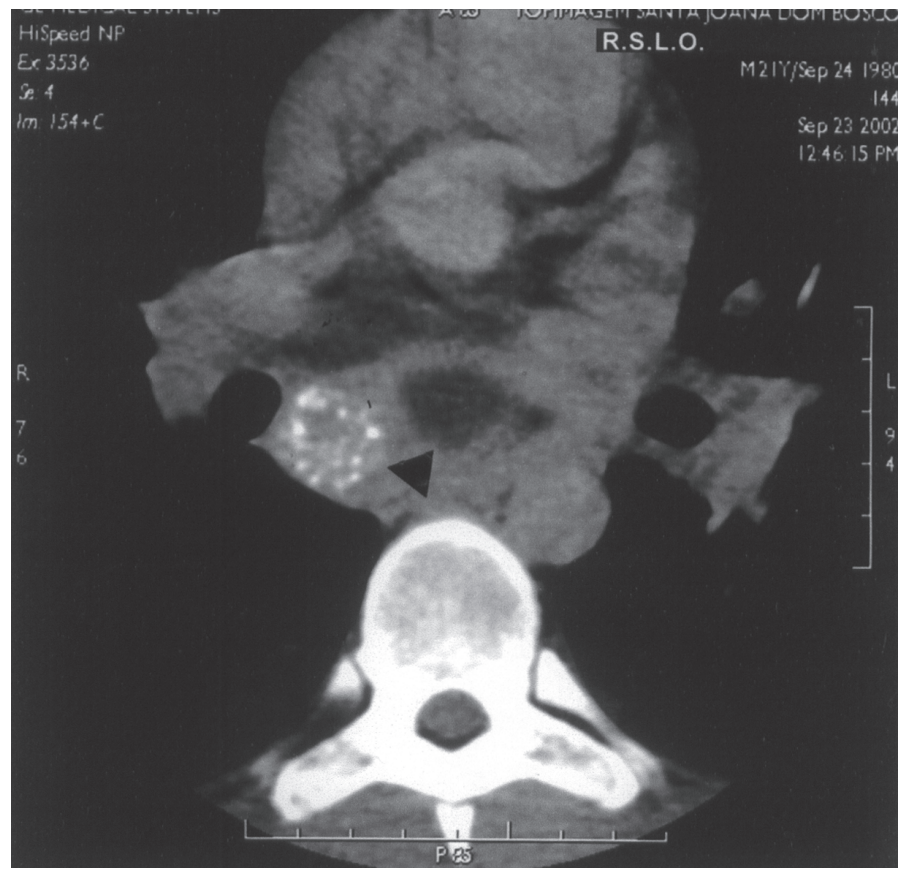

Fig. 2 - CASE 2: Contrast-enhanced computed tomographic scan of the chest demonstrates a $4.5 \mathrm{~cm}$ subcarinal mass with scattered calcifications (arrow).

One week after thoracotomy the patient was readmitted because he developed another episode of productive cough with foul-smelling purulent material associated with aspiration. On physical examination he appeared acutely ill. A chest radiograph showed bilateral aspiration pneumonitis. He was treated with a 3 -week course of liposomal amphotericin B and broad-spectrum antibiotics. His pulmonary symptoms and chest radiographic abnormalities resolved. Amphotericin $\mathrm{B}$ and the antibiotics were stopped, $200 \mathrm{mg}$ /day oral itraconazol was initiated and the patient was discharged. He remained in treatment for one year. Along with his clinical improvement, the immunodiffusion assay became negative. The patient has remained asymptomatic.

\section{DISCUSSION}

Relatively few cases of histoplasmosis with mediastinal involvement have been reported, and among these, only a very few have had discrete granulomas not complicated by surrounding fibrosis ${ }^{7}$ as was seen in the present cases. These complications occur when a caseous lymph node or the hyperreactive fibrous response involved in healing damages contiguous structures, leading to constrictive pericarditis, obstruction of the superior vena cava, tracheobronchial tree, pulmonary artery and veins, and esophagus, with formation of fistulas, commonly bronchopleural ${ }^{3,4}$. Occasionally, the caseous center may become liquefied and dissect into the tracheobronchial tree $e^{6,9,14}$, as observed in our second case.

Computed tomography is the preferred imaging technique in demonstrating mediastinal calcifications ${ }^{1}$. Calcification in association with histoplasmosis tends to be focal and scattered, greater than 10 $\mathrm{mm}$ in diameter, most often found in the right tracheal area, and is seen more than 10 years after initial infection ${ }^{6}$, as in the case of the second patient, who revealed close contact with chicken coop during his childhood.

In both of our cases, CT scans effectively demonstrated and localized the mediastinal granulomas ${ }^{11}$; however, the ultimate diagnosis was not suspected until the biopsies were analyzed. In patients with esophageal symptoms (dysphagia or odynophagia) mediastinal masses can be diagnosed by endosonography and endoscopic fine-needle aspiration biopsy ${ }^{13,15}$. Histologic analysis reveals granulomatous inflammation with centers of caseating necrosis. The specific diagnosis is made by methenamine silver staining that demonstrates yeast forms resembling $H$. capsulatum in small numbers in necrotic areas. Culture is usually negative ${ }^{14}$. Fungal serology may be of value in establishing the diagnosis, as observed in our second case, and can be used as a screening test $\mathrm{t}^{12,14}$. However, a negative result does not exclude histoplasmosis because of the low rate of serological positivity in mediastinal granuloma ${ }^{13}$. Differential diagnosis includes benign or slowly growing neoplasm, mediastinal cyst, tuberculosis and, rarely, sarcoidosis ${ }^{10,13}$. The presence of calcification supports the diagnosis of granulomatous infection ${ }^{11}$. Althought rare $^{2,9}$, histoplasmosis should be included in the differential diagnosis of mediastinal granulomas, although tuberculosis is more likely in regions non-endemic to the mycosis ${ }^{1}$.

\section{RESUMO}

\section{Histoplasmose mediastinal: relato dos dois primeiros casos brasileiros de granuloma mediastinal}

São relatados os dois primeiros casos de granuloma mediastinal por histoplasmose no Brasil, apresentando aspectos selecionados sobre dignóstico. O diagnóstico tecidual de histoplasmose foi obtido por mediastinoscopia e toracotomia, respectivamente. Em um paciente a massa calcificada subcarinal erodiu na árvore brônquica com pneumonite de aspiração bilateral uma semana após a toracotomia.

Embora rara, histoplasmose deve ser incluída no diagnóstico 

$105,2005$.

diferencial de granuloma mediastinal especialmente com calcificação maior do que $10 \mathrm{~mm}$ de diâmetro.

\section{REFERENCES}

1. AKMAN, C.; KANTARCI, F. \& CETINKAYA, S. - Imaging in mediastinitis: a systematic review based on aetiology. Clin. Radiol., 59: 573-585, 2004

2. BERNARD, A.C. \& MULLETT, T.W. - Mediastinal granuloma complicating histoplasmosis J. Ky med. Ass., 101: 12-14, 2003.

3. DAVIS, A.M.; PIERSON, R.N. \& LOYD, J.E. - Mediastinal fibrosis. Semin. resp. Infect., 16: 119-130, 2001.

4. GILLILAND, M.D.; SCOTT, L.D. \& WALKER, W.E. - Esophageal obstruction caused by mediastinal histoplasmosis: beneficial results of operation. Surgery, 95: 59-62, 1984 .

5. GOODWIN Jr., R.A. \& DES PREZ, R.M. - State of the art: histoplasmosis. Amer. Rev. resp. Dis., 117: 929-956, 1978.

6. GOODWIN Jr., R.A.; LOYD, J.E. \& DES PREZ, R.M. - Histoplasmosis in normal hosts. Medicine (Baltimore), 60: 231-266, 1981.

7. GOODWIN Jr., R.A.; NICKELL, J.A. \& DES PREZ, R.M. - Mediastinal fibrosis complicating healed primary histoplasmosis and tuberculosis. Medicine (Baltimore), 51: 227-246, 1972.

8. JERÔNIMO, A.L.C.; CORREA, J.C.; GONÇALVES, A.J.R.; BEZERRA, C.M.F. \& CUNHA, R.Q. - Mediastinite fibrosante por histoplasmose. Arq. bras. Med., 60: 129-131, 1986.
9. KAUFFMAN, C.A. - Pulmonary histoplasmosis. Curr. infect. Dis. Rep., 3: 279-285, 2001.

10. KERN, J.A.; DANIEL, T.M.; TRIBBLE, C.G.; SILEN, M.L. \& RODGERS, B.M. Thoracoscopic diagnosis and treatment of mediastinal masses. Ann. thorac. Surg., 56: 92-96, 1993.

11. LANDAY, M.J. \& ROLLINS, N.K. - Mediastinal histoplasmosis granuloma: evaluation with CT. Radiology, 172: 657-659, 1989.

12. MATHISEN, D.J. \& GRILLO, H.C. - Clinical manifestation of mediastinal fibrosis and histoplasmosis. Ann. thorac. Surg., 54: 1053-1057, 1992.

13. SAVIDES, T.J.; GRESS, F.G.; WHEAT, L.J.; IKENBERRY, S. \& HAWES, R.H. Dysphagia due to mediastinal granulomas: diagnosis with endoscopic ultrasonography. Gastroenterology, 109: 366-373, 1995.

14. WHEAT, L.J.; CONCES, D.; ALLEN, S.D.; BLUE-HNIDY, D. \& LOYD, J. - Pulmonary histoplasmosis syndromes: recognition, diagnosis, and management. Semin. resp. crit. care Med., 25: 129-144, 2004.

15. WIERSEMA, M.J.; CHAK, A. \& WIERSEMA, L.M. - Mediastinal histoplasmosis: evaluation with endosonography and endoscopic fine-needle aspiration biopsy. Gastroint. Endosc., 40: 78-81, 1994.

Received: 27 August 2004

Accepted: 18 January 2005 